\title{
O COMÉRCIO MARÍTIMO E ALGUNS ARMADO- DES DO SÉCULO XVIII, NA BAHIA (III).
}

\author{
(Continuação).
}

MARIEIA ALVES

Professôra do Instituto Feminino da Bahia.

Contemporâneos dos prestantes e prestigiosos armadores apontados nos artigos antecedentes, a todos uitrapassou em generosidade e relêvo social, o Mestre de Campo Teodósio Gonçalves da Silva. Sua prolongada permanência na Bahia, onde, desde 1713, já exercia atividades no setor do comércio marítimo, explica sua destacada posição, mantida até sua morte, ocorrida em 9 de maio de 1803 , aos 78 anos de idade.

Travamos conhecimento com a personagem em aprêço, no Arquivo da Santa Casa, em cujo quadro social foi admitido em 25 de maio de 1771, constando do Têrmo à página 385 , verso, do Livro 4.o, que era Cavaleiro da Ordem de Cristo e casado com D. Ana de Queiroz e Sousa. Aliás, documento do próprio punho desta senhora nos habilita a restabelecer seu verdadeiro nome - Ana de Sousa de Queiroz e Silva. Nenhuma informação quanto à filiação, naturalidade e profissão de Teodósio Gonçalves da Silva se encontra no Têrmo de admissão.

Mas não ficaria desconhecido êsse homem empreendedor e generoso, tantas vêzes seu nome aparece nos Arquivos religiosos e civis. Entretanto, para não cansar o leitor, ressaltaremos os fatos mais destacados da vida do homem de negócio, e as benemerências do ci.l'adão, com direitos à gratidão da Bahia .

Em 1769, Teodósio Gonçalves da Silva recebeu patente de confirmação no pôsto de Capitão da Companhia dos Familiares do Santo rfício da Capitania da Bahia, que vagara pela baixa de Manuel Fer"rndes Costa, ocupando dêste modo o pôsto mais elevado na Com-. Inhia, que contava, então, com 69 membros, entre comerciantes.

Anos depois, 1774, em virtude do cargo que ocupava, Teodósio " "unçalves da Silva recebeu ordens do General da Praça da Bahia para que a Companhia dos Familiares desse guardas para as portas 
dn Carmo. Sem dúvida, algo especial determinou a ordem em aprê(iv, tantos eram os privilégios que isentavam a Companhia de obrigações semelhantes, sendo a mesma subordinada, apenas, às ordens

, Governador.

Além das regalias concedidas aos Familiares, 'Teodósio Gonçalwiss da Silva gozava de vantagens que cercavam os Moedeiros, entre is quais girava seu nome.

Em 1775, Teodósio Gonçalves da Silva dirigiu um requerimento .. autoridade competente pedinto licença para construir nc estaleiro Real da Ribeira uma nau de 160 palmos de quilha, pela falta de capacidade nos estaleiros da Preguiça e da Ribeira de Itapagipe. Apesar da informação favorável do Governador Manuel da Cunha Menezes, o Intendente da Marinha, Rodrigo da Costa Almeida, não foi do mesmo parecer.

Isso não impediu que o ativo negociante possuísse 6 navios de grande lote, que navegavam para os portos do Reino, América, Äsia e Costa da Africa, segundo se lê em Novos Documentos para a História Colonial, de Francisco Borges de Barros, que, tendo exercido o cargo de Diretor do Arquivo Público da Bahia, escreveu baseado nas informações contidas no Livro de Cartas Régias. Borges de Barros acrescentou que Teodósio Gonçalves da Silva era natural da Província do Minho e senhor de latifúndios em Jaguaribe.

Confirma a excelência da frota do rico armador português a compra, pelo govêrno, do navio S. S. Sacramento e Nossa Senhora do Pilar, de sua propriedade, para ser armado em guerra e remetido para o Rio de Janeiro, datando de 5 de maio de 1777 o têrmo de avaliação do referido navio, que partiu da Bahia sob o comando do $\mathrm{Ca}-$ pitão-Tenente Francisco Xavier.

Pela correspondência trocada com Antônio Alves do Rio, sabemos que, em 1784, Teodósio Gonçalves da Silva se encontraya em Portugal. Vale reproduzir alguns trechos da carta, escrita da Bahia, em 30 de julho de 1784, ao Mestre de Campo:

... "Vão se augmentando muito as plantações do genero do café, cacáo e anil, de forma que antes de poucos annos serão estes generos de transporte para essa cidade. A arvore da pimenta que V.M. deu aos religiosos do Hospicio do Pillar, ha mais de 2 annos que tem dado pimenta tão perfeita como a da India e ha pena ou pouca curiosidade que tendo nós ahi uma arvore com certeza de dar pimenta não se tenha estendido esta planta, para hum dos generos principal do Brazil em que poderia dar queda á da India. Como a descuriosidade e preguiça reina e reinará sempre no Brazil, para huma cousa destas não era desacerto que o nosso Ministerio, com recommendação muito especial ao Governador, mandasse ordens muito apertadas para que os lavradores fossem obrigados, com 
penas graves a plantarem esta arvore, que antes de poucos annos haveria pimenta com abundancia" (*).

Por sua vez, escrevia Teodósio Gonçalves da Silva, de Portugal, para João Filipe, na Bahia, referindo-se à navegação para a Índia. e à decadência em que se encontrava o comércio da Costa da Mina.

Foi durante sua permanência em Lisboa, que ocorreu a Teodósio Gonçalves da Silva associar-se a seu sobrinho Antônio Dias de Castro Mascarenhas, estabelecendo-se na Côrte, como se vê do documento que passamos a transcrever:

Illm ${ }^{\circ}$. e $\operatorname{Exm}^{\circ} \mathrm{Snr}$.

"Em observancia da Real Carta de trez de Janeiro de mil sete centos e oitenta e cinco, que Sua Magestade foi servida expedir a beneficio do Mestre de Campo Teodozio Gonçalves Silva, e seo sobrinho Antonio Dias de Castro Mascarenhas, que se pretendem estabelecer nesta Corte, e Cidade de Lisboa, nomeey ao Dez.or Antonio Joaquim da Costa Corte Real, para Juiz de todas as dependencias que lhe dicesse respeito, e para Adjuntos os Dez.res Felipe Jorge de Faria, e Joaq.m Casimiro da Costa. Ao dito Antonio Dias da Costa Mascarenhas, mandei logo expedir o Passaporte, para com sua familia poder livremente seguir viagem. Deos g.e a V.exc.ia. Bahia a 16 de Julho de 1785.

Illm $^{0}$. Exm ${ }^{0}$ Senhor

Martinho de Mello e Castro

D. Rodrigo Jose de Menezes".

Não foi benéfica a permanência de Teodósio Gonçalves da Silva em Portugal. De volta à Bahia, em carta de seu punho de cópia difícil, sem data e sem indicação da pessoa a quem foi dirigida, pois dela consta apenas a indicação - Ilmo. Exmo. Snor - diz o Mestre de Campo, que nada tinha de homem de letras:

... "Eu cheguei a esta cidade com 52 dias de viagem, e sempre com boa saude e toda a minha familia; e aqui vim achar a minha casa no maior desarranjo a que podia chegar, por estar ... ja fazido de conta que eu cá não vinha mais" . .

Em 1787, Teodósio Gonçalves da Silva pretendeu o direito da arrendação do tabaco, antigo privilégio da família Pires de Carvaiho e Albuquerque, que se movimentou para conservar a posse dêsse direito, através de vários requerimentos e representações. Num dèstes documentos, diz o requerente:

Que a dita casa de arrecadação está situada no coração da Cidade Baixa, que forma o principal corpo do comércio, á vista e face da justiça e milicia, para evitar os contrabandos daquelle genero,

(*). - Respeltadas a grafia e a redaçáo. 
lembrados na regia provisão expedida pelo Tribunal da Junta do tabaco em 26 de novembro do anno de 1770 , que demonstra a certidão n. 1. Que a dita casa de arrecadação tem hum porto abrigado e com fundo sufficiente.

"Que o trapiche de Theodosio Gonçalves Silva, conhecido com a denominação de trapiche de Barnabé Cardoso, por ter sido seu fundador, fica no fim da marinha mercante, longe do principal corpo do commercio, pela sua situação muito proprio para os contrabandos...".

José Pires de Carvalho e Albuquerque alegou ainda que o pretendente ao direito de arrecadação do tabaco era rico,

"pelas suas interessantes negociações",

não tinha filhos, conseguindo, por fim, sentença a seu favor.

Das atividades do homem de negócios muito já dissemos. Acompanhemos, agora, os passos do cidadão benemérito.

Em 1796, Teodósio Gonçalves da Silva ocupava o cargo de Provedor da Santa Casa, instituição esta em situação financeira angustiosa. O momento era propício para que o Provedor -

"rico pelas suas interessantes negociações e sem filhos" -

pusesse à prova a nobreza do seu coração.

O Livro 2.o Registro, do Arquivo da Santa Casa, incumbiu-se de nos revelar o gesto do velho Mestre de Campo, através dêste:

"Registo do Escrito de doasão de cento e vinte mil cruzados q.o Provedor da Santa Casa de Misericórdia o Me. de Campo Theodozio Gonçalves Silva e sua m.er deu de esmola a m.a S.ta Caza.

"Por este p.r hum de nos feito e p.r ambos assinado dizemos nos o Mestre de Campo Theodozio Gonçalves Silva e D. Anna de Souza de Queiros e Silva que muito de nossa livre vontade sem constrangimento de pessoa alguma, q.e nos somos senhores de varias dividas q.se nos deve, tanto nesta cidade como p.lo reconcavo dela pr.Escrituras, reditos e a mayor parte por execusoens que corre no cartorio da Moeda desta Cidade de que he Escrivão Vicente Ferreira Antunes as quaes todas perfazem a quantia de cento e vinte mil cruzados, que são quarenta e oito contos de reis como consta da lista junta, cuja quantia he a importancia porque vendi a propriedade q.nos em outro tempo quizemos dar a Santa Caza da Mizer.a e p.r q.naquelle tempo os Irmãos da Meza não quizerão aceitar ficou a dita Sta. Caza sem este beneficio, e porque agora de prezente foy Deos Nosso Senhor servido q.me fizesse Prov.r da Dita Sta. Caza e reconhecendo nos ditos doadores, q.devemos tantos beneficios a Deos Nosso Senhor p.r nos ter beneficiado tanto 
sem termos mericimentos dezejando satisfazer de modo pocivel as nossas obrigasoins, somos contentes que todas estas dividas q.se nos estão devendo de hoje em diante pasem p.a a dita Santa Caza da Mizericordia p.a a cobrar como suas q'he e ficão sendo p.r vertude desta doasão..." (*).

A Santa Casa, pelos seus dirigentes, apreciou à justa o gesto nobre do velho Provedor e de sua espôsa, que se vêem esplêndidamente retratados no Salão Nobre. Êle, de pé, vestido à moda do fim do século XVIII, ostenta no peito a insígnia de Cavaleiro da Ordem de Cristo, e entrega a D. Ana um pergaminho para assinar. Ela, sentada à direita do marido, veste saia enfunada - balão - corpete ajustado, pequeno chapéu, dois cachos de cabelos sôbre os ombros. As jóias que a adornam atestam a riqueza do casal. Com a mão direita segura uma caneta e com a sinistra conchega ao coração um ramo de rosas. O simbolismo é perfeito.

Não encontramos indicação do autor dêsse retrato.

Em Diário da viagem ao norte do Brasil, do Imperador D. Pedro II, lê-se à página 90, a propósito dos retratos, que o visitante ilustre viu no Salão Nobre da Santa Casa e anotou, baseado nas informações colhidas na ocasião:

"... e o de Teodózio Gonçalves, que tendo doado grande soma ao Recolhimento e hesitando a administração em aceitar a doação por não ter o doador o juízo muito no seu lugar, a mulher dêste assina também a doação, o que indica as duas figuras de homem e de mulher, pegando aquêle num papel e esta numa pena".

O documento de doação dos cento e vinte mil cruzados desmente a informação dada ao Imperador sôbre a saúde mental do vetho Mestre de Campo, quando se achava à frente dos destinos da Santa Casa e tão generoso se mostrou.

Não foi êsse o gesto único do Casal Teodósio-Ana, que continuou a missão de fazer o bem, passando êle embora pela fama de não ter 0

$$
\text { "juízo muito no seu lugar". }
$$

$\mathrm{O}$ escritor Henrique Fontes, em $O$ Irmão Joaquim, o Vicente de Paulo brasileiro, livio em que exalta a memória de Joaquim Francisco do Livramento, conta-nos que êste apóstolo da caridade ao chegar à Bahia, em 1798,

"A novas instâncias que, certamente, the terão feito caridosos conhecidos seus, juntou-se agora a positiva animação de Teodoro (Teodésio) Gonçalves da Silva e de sua mulher d.Ana de Sousa de

(*). - Como sempre, respeitamos a redąão e a grafia, ambas incorretas. 
Queirós e Silva, os quais, tendo em vista a grande necessidade que havia na Cidade de um seminário tendente à perfeita educação de um e de outro sexo como prelúdio mais. certo e evidente dos bons ou maus costumes que no decurso dos anos adquirem "e" atentas ùnicamente à honra de Deus Caridade dêstes inocentes e bem público da mesma Cidade",

se comprometeram, por escritura de 10 de maio de 1789 , a fornecer-lhe recursos para reedificação e estabelecimento da casa que servira de noviciado dos jesuítas, conforme já se tinha pediclo a Sua Majestade. Constituiam tais recursos na doação de um título de dívida de oito contos de réis ao juro de lei e de mais

\footnotetext{
"duas moradas de casas de sobrado, novas, com suas lojas e chãos anexos, tanto nos fundos como na ilharga, para outro sobrado, perfazendo-se a doação desde que do donatário conseguisse o beneplácito régio para a conclusão do seminário".
}

Homem experimentado, não agia sem as precauções necessárias, tanto assim que data de 17 de junho de 1778 a provisão régia pela qual the foi concedida autorização para dispor, em vida, de seus bens a favor da Santa Casa e a fazer outros donativos.

Com o pensamento sempre voltado para o bem, em 1799, 'Teodósio Gonçalves da Silva e sua mulher dirigiram um requerimento ao Governador D. Rodrigo de Sousa Coutinho, pedindo licença para fundar no antigo noviciado dos jesuítas um seminário ou colégio de meninos e um recolhimento de meninas órfãs, junto à capela de Nossa Senhora da Lapa.

Para o indispensável despacho, o Governador procurou informações do Arcebispo D. Frei Antônio Corrêa, que se pronunciou favoràvelmente, em fevereiro de 1799.

Ao que tudo indica, a saúde mental do Mestre de Campo era normal e assim continuava em 1801, disso nos certificando complicado caso de família, para cuja solução Teodósio e a espôsa foram convocados pelo Doutor Ouvidor e Provedor da Comarca Manuel Vieira de Mendonça para, na qualidade de padrinhos, deporem a respeito da maioridade de uma sobrinha de ambos, cujo assento de batismo não foi encontrado .

Nessa oportunidade, Teodósio Gonçalves da Silva declarou que contava 76 anos de idade. Por sua vez, D. Ana disse contar 54. Falecendo 2 anos depois, em 1803, segue-se que o primeiro alcançou jdade provecta -78 anos. Ambos assinaram de próprio punho.

O rumoroso caso de família, que envolveu o casal Gonçalves da Silva, girou em tôrno da herança das jovens Ana de Sousa Queiroz e Castro e Maria do Carmo de Queiroz e Castro, filhas de Antônio Dias de Castro Mascarenhas, sobrinho do Mestre de Campo, 
e da falecida mulher daquele, D .Maria Vitorina de Jesus, irmá da espôsa de Teodósio Gonçalves da Silva.

As jovens, maiores de 21 anos, pretendiam administrar os bens herdados da mãe, contra o que se insurgia seu pai, Antônio Dias de Castro Mascarenhas.

Trata-se de questão longa e renhida, que nada teria a ver com o nosso assunto, se Antônio Dias não procurasse interferir nos negócios de seu tio, em requerimento no qual, alegando avançada idade e demência, pedia que fôssem nomeados dois negociantes para administrarem sua casa comercial, a fim de evitar-lhe a ruína... e o seu prejuízo!

Por sua vez, D. Ana de Sousa Queiroz e Silva pleiteou a administração dos bens de sua casa, sob pretexto da avançada idade do marido e doença. Ela própria foi dada como dissipadora de seus bens.

Em vista da luta das jovens Ana e Maria do Carmo, por motivo da herança materna, luta em que se empenharam tenazmente, e de outras questões provocadas por Antônio Dias de Castro Mascarenhas com parentes, entre os quais seus cunfiados José Pinheiro de Queiroz, D. Ana de Sousa de Queiroz e Silva e outros, julganıos que, a interêsses de herança, se deve a fama de não ter o Mestre de Campo

"o juizo muito no seu lugar".

Na verdade, não tendo filhos, a generosidade do casal Gonçalves da Silva prejudicava os herdeiros colaterais.

Julgamos, entretanto, provado que, até 1801, Teodósio Gonçalves da Silva estava com saúde mental em condições normais, não se justificando a informação dada ao Imperador.

Os têrmos da doação feita à Santa Casa, em 1796, e de outras, que se seguiram, atestam equilíbrio e falam de um coração magnânimo e agradecido a Deus, pelos benefícios recebidos - sem merecimento - segundo acrescentou.

D. Ana de Sousa Queiroz e Silva, mais nova do que o marido 22 anos, faleceu em 4 de abril de 1812.

Compulsamos no Arquivo Público do Estado seu volumoso inventário, cujas extraordinárias despêsas falam da opulência, apesar das generosas doações, que perpetuam seu nome e o do velho Mestre de Campo nos anais da assistência social na Bahia.

(Continua). 